\title{
Bridging the Library and Information Science Research - Practice Gap: A Panel Discussion
}

\author{
Helen Partridge \\ University of Southern \\ Queensland \\ Toowoomba, Australia \\ helen.partridge@usq.edu.au \\ George Buchanan \\ University of Melbourne \\ Melbourne, Australia \\ george.buchanan@unimelb.edu. \\ $\mathrm{au}$ \\ Dana McKay \\ University of Melbourne \\ Melbourne, Australia \\ dana.mckay@unimelb.edu.au
}

\author{
Lisa M. Given \\ Swinburne University of \\ Technology \\ Melbourne, Australia \\ lgiven@swin.edu.au
}

Kate Bunker

Australian Library and

Information Association

Canberra, Australia

Kate.Bunker@alia.org.au

\author{
Bhuva Narayan \\ University of Technology \\ Sydney \\ Sydney, Australia \\ Bhuva.Narayan@uts.edu.au
}

\author{
Elham Sayyad Abdi \\ University of Southern \\ Queensland \\ Toowoomba, Australia \\ elham.sayyadabdi@usq.edu.au \\ Edward Luca \\ University of Sydney \\ Sydney, Australia \\ edward.luca@sydney.edu.au
}

\begin{abstract}
The panel will explore the challenges and opportunities for bridging the library and information science (LIS) research practice gap in Australia. The panel brings together participants from the Research Assistance and Development for Australian Researchers (RADAR) Grant, an initiative of the Library and Information Science Research Australia (LISRA) project. The LISRA project is a three-year project aimed at encouraging and enabling research culture and practice within the Australian LIS sector.
\end{abstract}

\section{KEYWORDS}

research practitioners, research engagement, library and information science research, research-led practice,

\section{ASIS\&T THESAURUS}

Australia, Research and Development,

\section{INTRODUCTION}

It is frequently noted that there is a divide between research and practice in library and information science (LIS) (Booth, 2003; Crowly, 2005; Haddow and Klobas, 2004); McMenemy, 2010). LIS researchers lament that practitioners are not applying research findings, and LIS practitioners say research is too "ivory tower" and not relevant to practice. Although there may be some truth to these statements, there are many points of collaboration and application of research across the sector, worldwide.

The purpose of this panel is to explore how LIS practitioners and researchers, as well as professional associations, can work together to bridge the research practice gap, and in so doing continue to advance the LIS profession and its impact on the individuals and communities we support. To achieve this purpose, the panel will include key stakeholders from the Research Assistance and Development for Australian Researchers (RADAR) Grant, an initiative of the Library and Information Science Research Australia (LISRA) project. In addition, to reviewing the panelists' "lessons learned", a broader discussion with attendees will explore the current challenges and opportunities for practitioners and researchers working together in LIS contexts. Although situated in the Australian context, the RADAR initiative, and the experiences of its key stakeholders, can provide insights to the LIS sector internationally.

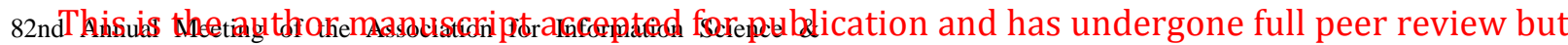

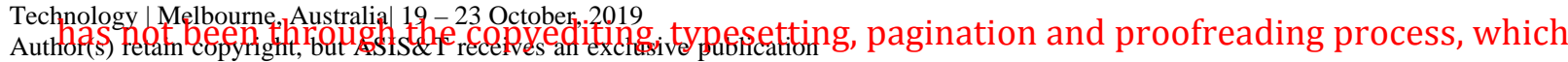
licensf ay lead to differences between this version and the Version of Record. Please cite this article as doi: $10.1002 /$ pra2.92 
LIBRARY AND INFORMATION SCIENCE RESEARCH AUSTRALIA (LISRA)

Library and Information Science Research Australia (LISRA) is a three-year project funded by the Australian Research Council. The project aims to encourage and enable research culture and practice within Australia's library and information science (LIS) profession. LISRA is being led by the University of Southern Queensland and Swinburne University of Technology, in partnership with the Australian Library and Information Association (ALIA) and National and State Libraries Australia (NSLA). More details on the project can be found at the website (http://lisresearch.org.au) or Twitter (@LISResearchAU).

Research Assistance and Development for Australian Researchers (RADAR) Grant

The Research Assistance and Development for Australian Researchers (RADAR) Grant was developed as part of the LISRA project to foster collaborative research in Australia's LIS sector. The RADAR grants were designed to provide: (i) research funding to teams of academics and practitioners to explore a research problem that will contribute to knowledge and practice in LIS; and (ii) a supportive network of academics and practitioners to foster engagement and build capacity in LIS research practice.

All LIS academics and LIS practitioners living in Australia were eligible to apply. Projects were required to have a minimum of two people (an LIS academic and an LIS practitioner) to serve as "team co-leads". Projects could include other team members, including those drawn from other disciplines or other professional contexts, as needed to meet the project goals. Successful applications received up to $\$ 15,000$ AUD to support the research activities.

All applications were evaluated by the LISRA Advisory Board using the following evaluation criteria:

- Is the project clearly described, is the problem well defined and grounded in the relevant literature, and is the research aim clearly stated?

- Is the project designed to be successfully completed within one year?

- Is the proposed approach, including the methodology/method(s) appropriate, and are the investigative procedures clearly explained?

- What is the significance of the proposed research to the library and information science community?

- Are outcomes, impact and deliverables specifically identified?

- Are sufficient resources and expertise available?
- Is there institutional commitment as evidenced by cost sharing to support the project?

Thirteen applications were received with three funded. The projects were conducted during the 2017 calendar year. The successful applicants participated in a range of activities that would assist in building a community of practice, as well as promoting and sharing experiences, and the findings of the research, within the Australian IS sector. The activities included, but were not limited to:

- Regularly (virtual) meetings throughout 2017 to guide project development (e.g. workshops on project management, recruiting, dissemination)

- $\quad$ Three blog posts posted to the LISRA website during 2017

- Attendance at the August 2018 the joint Australian and New Zealand LIS conference to disseminate project findings.

- A full paper submission on the project to a scholarly LIS journal

- Participation in a free online seminar to disseminate project findings.

The Three RADAR Projects

The three research projects funded by the RADAR Grant scheme were:

\section{Non-library user immigrants: How can libraries support} their information experience?

An understanding of people's engagement with information in any specific context can inform the design and development of interventions (e.g. programs, services) that support individuals' information needs in that context. This project, in two (i) research and (ii) implementation phases, investigated (i) non-library user refugees' engagement with information, and (ii) how a case public library applied the findings to refine their services and program. The outcome was a set of recommendations for service and program refinement in the case library in order to enable it to more comprehensively address the identified ways of engagement with information among the target population. Future implementation of the recommendations ensures that the experience of non-library user clients from the refugee background is recognised, supported in more effective ways and therefore enhanced by the library. Such enhancement in refugees' information experience empowers them for more informed and inclusive citizenry and provides libraries with an opportunity to contribute to the realisation of social inclusion within the society. 
This project was undertaken by LIS researchers, Elham Sayyad Abdi, from the University of Southern Queensland and Kathleen Smeaton from the University of Queensland, in collaboration with Debra Cooper, an LIS practitioner from Logan City Council.

\section{We're all in this together: investigations of a single presentation for books in all formats}

Libraries invest heavily in ebooks, but these resources are often underutilized. One of the reasons for this lack of uptake is based on user preference for browsing physical shelves when information seeking. Making ebooks in some way 'visible' at the library shelves is likely to improve both the uptake of ebooks, and user experience of the library. The purpose of this project was to create a blended library experience at the library shelves: the project team created software that when a user scanned the barcode of a physical book with their mobile phone returned topically related ebooks held by the library. In testing, the users surprised the research team: while this software was used at the library shelves, it was also used in other locations such as bookshops and users' homes. In addition to providing a blended library, the software was repurposed by users to take the library to a range of locations in their lives.

This project was undertaken by George Buchanan an LIS researcher at the University of Melbourne, in collaboration with Dana McKay an LIS researcher practitioner from Swinburne University of Technology.

The Role of Academic Libraries in Promoting Scholarly Communication Literacy: An Exploration of Open Access, Researcher Identity and Social Impact

This project examined issues relating to the perceptions and adoption of open access (OA) and institutional repositories (IR). The team used a survey research design to gather data from academics and other researchers in the humanities, arts and social sciences (HASS). The findings suggest that HASS researchers are highly influenced by traditional measures of quality, such as journal impact factor, and are less concerned with making their work more findable or promoting it through social media. This highlights a disconnect between researchers' desired outcomes and their efforts towards promoting their work. The findings also suggest that institutional policies have the potential to increase OA awareness and adoption. The team recommend that academic librarians engage with faculty through outreach and workshops to change perceptions of OA and the institutional repository.
The project was undertaken by a team of LIS practitioners and LIS researchers from the University of Technology Sydney: Bhuva Narayan, Senior Lecturer; Edward Luca, Academic Liaison; Mal Booth, University Librarian; Belinda Tiffen, Director of Library Resources; and, Ashley England, Leader of the Arts and Social Sciences Team.

\section{PANEL OVERVIEW}

This panel brings together key stakeholders from the RADAR Grant scheme to discuss their experiences in the design delivery of a research project that involved both LIS practitioners and LIS academic researchers. Each team combined research and practice in their own way, bringing a diversity of perspectives to the challenge of combining research with practice. The panel will also involve audience members in an interactive discussion by exploring all attendees' experiences of the challenges and opportunities for bridging the research-practice gap in LIS. This panel aims to foster conversations that will continue well after the session has finished.

\section{The Panelists}

Each panelist contributes unique insights to the proposed panel based on their experience as members of the LISRA project, and the RADAR scheme, and their research and practice in the LIS context.

Dr Helen Partridge is Professor and Pro Vice-Chancellor (Education) at the University of Southern Queensland. She is an adjunct Professor in the School of Information Systems, Queensland University of Technology, Australia. Helen is an active member of the Australian and international library and information profession. She has twice been elected to the Board of Directors of the Australian Library and Information Association, and was appointed a Fellow of the Association in 2012. Helen has been the secretary for the Library Theory and Research Standing Committee of the International Federation of Library and Information Associations, and coordinated the committee's project, Research Librarian Partnership, a mentoring program aimed at helping new professionals in the library sector develop their knowledge, skill and experience in undertaking research. Helen has received over \$2 million AUD in research funding; her work focuses on the interplay between information, learning and technology. From 2009 to 2011 she worked with 11 Australian educational institutions on a project that established a framework for the education of the information professions in Australia for the twenty-first century. She has been a visiting Fellow at the Oxford Internet Institute, University 
of Oxford (2011) and the Berkman Center for Internet and Society and Society, Harvard University.

Dr. Lisa M. Given is Professor of Information Science and Associate Dean, Research and Development, for the Faculty of Health, Arts and Design at Swinburne University of Technology, Australia. She is a Past-President of the Association for Information Science and Technology and has served on the College of the Australian Research Council. Lisa is an Adjunct Professor in the School of Information Studies, Charles Sturt University (Australia), as well as in the Faculty of Arts (Digital Humanities), University of Alberta (Canada). A former Director of the International Institute for Qualitative Methodology (Canada), Lisa has received numerous grants and awards. She is Lead Investigator of a current ARC Linkage Project exploring research adoption by the wine industry and of an ARC Discovery Project looking at knowledge management practices in non-profit organizations. Lisa is also coinvestigator for the ARC Linkage Project "Library and Information Science Research Australia," where she codeveloped the Research Assistance \& Development Australian Researchers Grant Program to provide a series of supportive activities to foster research collaboration in library and information science. She is co-author (with Donald O. Case) of Looking for Information: A Survey of Research on Information Seeking, Needs, and Behavior (2016, 4th edition).

Dr Elham (Ellie) Sayyad-Abdi is an information researcher. She has served as an Australian Fulbright Scholar-In-Residence at the University of the Pacific, California (AY 2018/19) and a lecturer in the Master of Information Science, Queensland University of Technology, Australia. A former convenor of the LIS Education in Developing Countries Special Interest Group at IFLA, and the secretary of the ASIS\&T Asia-Pacific chapter, Ellie is currently co-chairing the Research Advisory Committee at the Australian Library and Information Association (ALIA). Her research interests lie in information experience, information literacy, social justice and translation of research to practice.

Dr George Buchanan is Associate Professor and Director of the University of Melbourne iSchool. His research is focused on how technology can help people find information more effectively, and spans mobile usability, search technology and psychology. He previously led the Centre for Human-Computer Interaction Design at City, University of London. He has made major contributions to the Greenstone Digital Library software, which is in use by over 200,000 organisations worldwide. His current interests include how physical and digital libraries can boost creative problem solving and how to improve privacy and security online.

Kate Bunker AALIA (CP) is Director of Learning at the Australian Library and Information Association (ALIA). In this role, she manages ALIA education and professional development policies and guidelines including ALIA course accreditation. Kate is also interested in assisting library and information science professionals become LIS practitioner researchers.

Dr Dana McKay recently finished her $\mathrm{PhD}$ in information interaction, looking at how people browse for books. This work was born of ten years' practical experience as a user experience professional in an academic library, where the project described in this submission took place. Dana worked on a range of challenges in her professional role, including making user-centric interface decisions while implementing web scale search, understanding how readers approached the shelves, and understanding how library users used the study space available in the library. Dana's current research is similarly information focused and industry-engaged; she is working on information seeking and use problems with GLAM sector industry partners.

Edward Luca is a library practitioner and researcher. He is currently Manager, Academic Services (Medicine and Health, Health Sciences) at the University of Sydney Library. He previously worked as an Academic Liaison Librarian, and before that was Communication Officer at the University of Technology Sydney (UTS) Library. Edward writes and speaks on topics including information literacy, scholarly communication and user experience.

Dr Bhuva Narayan is a Senior Lecturer and Discipline Head for the Information and Knowledge Management Program at the University of Technology Sydney (UTS), Australia. She completed an MLIS from the iSchool at the University of Pittsburgh and a PhD from the Queensland University of Technology (QUT), Australia. Her research interests are in information behavior, human learning, design thinking, social media, open access, and social justice.

\section{Structure of the Panel}

\begin{tabular}{l|l}
\hline $\begin{array}{l}\text { Time (in } \\
\text { minutes) }\end{array}$ & Activity \\
\hline
\end{tabular}




\begin{tabular}{|c|c|}
\hline $\begin{array}{l}\text { Time (in } \\
\text { minutes) }\end{array}$ & Activity \\
\hline 5 & $\begin{array}{l}\text { Helen Partridge will introduce the panel } \\
\text { and provide an overview of the LISRA } \\
\text { project. }\end{array}$ \\
\hline 5 & $\begin{array}{l}\text { Kate Bunker will discuss why ALIA } \\
\text { became involved in the LISRA project and } \\
\text { how it benefits and impacts the work of } \\
\text { ALIA and the Australian LIS profession. }\end{array}$ \\
\hline 5 & $\begin{array}{l}\text { Lisa Given will provide an overview of the } \\
\text { RADAR scheme. }\end{array}$ \\
\hline 25 & $\begin{array}{l}\text { The members of the three RADAR funded } \\
\text { projects will provide a brief overview of } \\
\text { their projects, with particular focus on } \\
\text { development and implementation of a } \\
\text { collaborative team involving both LIS } \\
\text { practitioners, and LIS researchers. }\end{array}$ \\
\hline 30 & $\begin{array}{l}\text { Together the panelists will facilitate an } \\
\text { interactive discussion. In small groups of } 5 \\
\text { to } 6 \text {, attendees will consider the following } \\
\text { three questions in the context of building a } \\
\text { culture and practice of LIS practitioner and } \\
\text { LIS research collaboration: (i) one thing } \\
\text { that does not foster collaboration and } \\
\text { should be stopped; (ii) one thing that needs } \\
\text { to be started to increase collaboration; (iii) } \\
\text { one thing that works well and should be } \\
\text { kept. }\end{array}$ \\
\hline 15 & $\begin{array}{l}\text { Each group will report back stating the top } \\
2 \text { responses to each of the three questions. }\end{array}$ \\
\hline 5 & $\begin{array}{l}\text { Lisa Given will review key points from the } \\
\text { presentations and discussion. }\end{array}$ \\
\hline
\end{tabular}

\section{REFERENCES}

Booth, A. (2003), Bridging the research-practice gap? The role of evidence-based librarianship, New Review of Information and Library Research, 9(1), 3-23.

Crowly, C. (2005) Spanning the theory-practice divide in library and information science. Scarecrow Press. UK.

Haddow, G. \& Klobas, J. (2004). Communication of research to practice in library and information science: Closing the gap. Library \& Information Science Research, 26(1). 29-43.
McMenemy, D. (2010). Fostering a research culture in UK library practice: barriers and solutions. Library Review, 59(5). 321-324. 


\section{University Library}

\section{- M M N E R VA A gateway to Melbourne's research publications}

Minerva Access is the Institutional Repository of The University of Melbourne

Author/s:

Partridge, H;Given, LM;Abdi, ES;Buchanan, G;Bunker, K;Luca, E;McKay, D;Narayan, B

Title:

Bridging the library and information science research - practice gap: A panel discussion

Date:

2019-01-01

Citation:

Partridge, H., Given, L. M., Abdi, E. S., Buchanan, G., Bunker, K., Luca, E., McKay, D. \& Narayan, B. (2019). Bridging the library and information science research - practice gap: A panel discussion. Proceedings of the Association for Information Science and Technology, 56, (1), pp.561-564. Wiley. https://doi.org/10.1002/pra2.92.

Persistent Link:

http://hdl.handle.net/11343/285239 